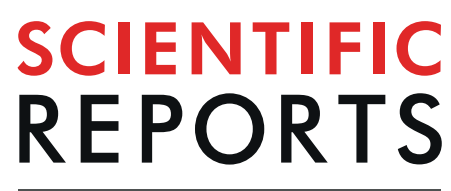

natureresearch

\title{
Self-assembled kanamycin antibiotic-inorganic microflowers and their application as a photocatalyst for the removal of organic dyes
}

\author{
Ratan W. Jadhav ${ }^{1,5}$, Duong Duc La², ${ }^{2}$, Vishal G. More ${ }^{1}$, Hoang Tung Vo ${ }^{3}$, Duy Anh Nguyen ${ }^{2}$, \\ Dai Lam Tran ${ }^{4}$ \& Sheshanath V. Bhosale $\mathbb{( I D}^{1 *}$
}

Construction of hybrid three-dimensional (3D) hierarchical nanostructures via self-assembly of organic and inorganic compounds have recently attracted immense interest from scientists due to their unique properties and promise in a large range of applications. In this article, hybrid flower structures were successfully constructed by self-assembly an antibiotic, kanamycin, with $\mathrm{Cu}^{2+}$. The flower-like morphology was observed by scanning electron microscopy, to be approximately $4 \mu \mathrm{m}$ in diameter and about $10 \mathrm{~nm}$ in thickness. FTIR spectroscopy and X-ray diffraction confirmed the antibiotic-inorganic hybrid structure was uniform composition, and showed crystallinity due to ordered self-assembly. The hybrid flowers showed high photocatalytic activity towards degradation of methyl blue during 240 minutes under visible light irradiation. A possible mechanism of photocatalytic activity was also proposed, that exposes the inherent advantages in using antibiotic-inorganic hybrid flowers as photocatalysts, where self-assembly can be used to generate active, high surface area structures for photodegradation of pollutants.

Recently, intensive attention has been focused on methods to tailor the morphology of nanostructured materials such as core/shell nanoparticles, nanoplates, nanowires, nanofibers, nanotubes and nanoflowers ${ }^{1-5}$. With the extensive possibility of applications in gas sensing, photocatalysis, energy storage, adsorption, chemical and biological sensing, separation, flower-like structures have been intensively studied in recent years ${ }^{6,7}$ Three dimensional flower-like morphologies in particular can be constructed from various materials such as metal oxides, hydroxides ${ }^{8}$, carbon-based materials ${ }^{5,9,10}$, and other materials ${ }^{11-13}$. These flower-like structures have a high ratio of surface to volume, which can be effectively utilized in many applications including, but not limited to, chemical and biological sensing, catalysis, and adsorption ${ }^{14-17}$. Even though many approaches have been employed to fabricate three-dimensional flower-like structures, conventional synthetic methods are complicated, involving strictly controlled conditions such as inert media, high temperature, use of toxic chemicals or high pressure. Thus, finding a simple and cost-effective approach for the synthesis of three-dimensional flower-like structures is worthy of further research.

In the field of advanced nanomaterial fabrication, self-assembly has attracted considerable attention due to the possible formation of dynamic and complex systems from basic building blocks, and may afford materials for applications in areas such as sensors, energy storage, and optics ${ }^{18-22}$. Among the classes of self-assembled nanostructures, organic and inorganic compounds can be spontaneously integrated as different components via hierarchical self-assembly to obtain hybrid materials ${ }^{23-25}$. In particular, several three-dimensional functional hybrid flower-like structures had been created via self-assembly ${ }^{24,26-28}$. Ge et al. used the inorganic component of copper (II) ions with various proteins as the organic component to fabricate hybrid organic-inorganic nanoflowers ${ }^{29}$. The

\footnotetext{
${ }^{1}$ School of Chemical Sciences, Goa University, Taleigao Plateau, Goa, 403 206, India. ${ }^{2}$ Institute of Chemistry and Materials, Hanoi, Vietnam. ${ }^{3}$ Environmental Institute, Vietnam Maritime University, Haiphong city, Vietnam. ${ }^{4}$ Institute of Tropical Engineering, Vietnam Academy of Science and Technology, Hanoi, Vietnam. ${ }^{5}$ These authors contributed equally: Ratan W. Jadhav and Duong Duc La. *email: svbhosale@unigoa.ac.in
} 


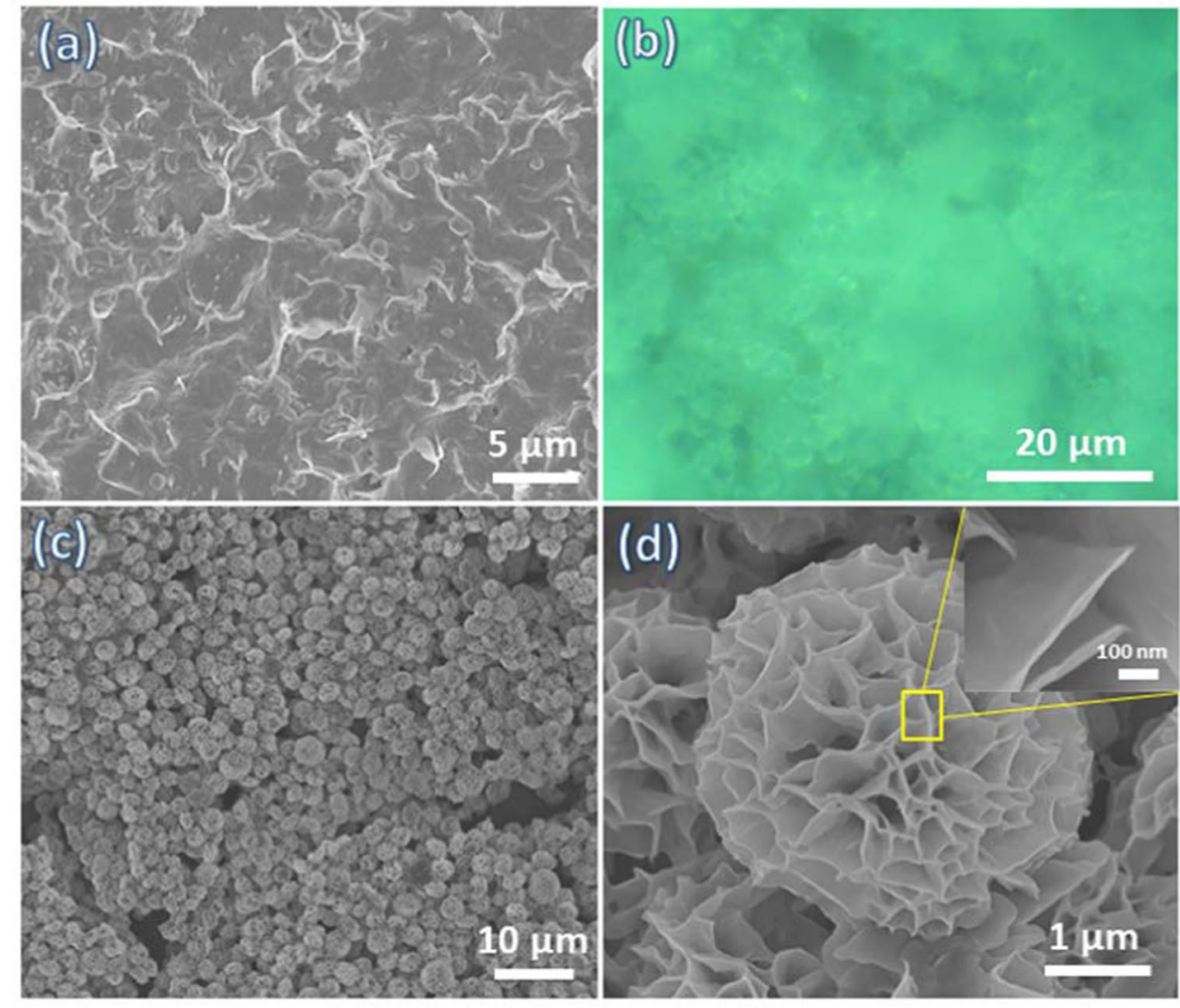

Figure 1. SEM images of solids obtained from (a) $\mathrm{Cu}_{3}\left(\mathrm{PO}_{4}\right)_{2} \cdot 3 \mathrm{H}_{2} \mathrm{O}$ crystal, (b) optical image and (c, d) SEM images of kanamycin- $\mathrm{Cu}_{3}\left(\mathrm{PO}_{4}\right)_{2}$ hybrid flowers.

main driving force for formation of flower-like morphology was the interaction between the protein and copper ion, and the resultant hybrid flower showed enhanced enzymatic stability and activity compared to that of the free enzyme. In another study, 3D nanoflowers were successfully fabricate by using copper(II) ions as the inorganic component self-assembled with various biosurfactants as the organic component ${ }^{30}$. The mechanism of growth of nanoflower in this instance was complex formation between the biosurfactant molecules and the copper ions, and these complexes then became nucleation sites for primary crystals of copper phosphate, which indicate that the interaction between biosurfactant and copper ions leads to the petal formation, shaping into three-dimensional nanoflowers. These organic-inorganic hybrid nanoflowers were of high stability and displayed catalytic activity for the degradation of cationic dyes.

Antibiotics of the aminoglycoside type (e.g., tobramycin, kanamycin, neomycin B) are formed by the link between two amino sugar molecules with an aminocyclohexanol unit by glycosidic bonds. The amine groups in antibiotics can form molecular complexes with various metal ions or inorganic compounds. Inspired from self-assembly in nature, herein we propose a facile approach to fabricate antibiotic-inorganic hybrid flowers via self-assembly, using copper ions as inorganic component and kanamycin (an antiobiotic) as the organic component. The complexation of copper ions with kanamycin are responsible for nucleation and growth of the flower-like structures. The photocatalytic behavior of the three dimensional inorganic-organic hybrid materials was investigated for the first time along with a brief explanation of the possible photocatalytic mechanism.

\section{Results and Discussion}

The hybrid flower-like structures were fabricated by adding Kanamycin molecules, one of the most commonly used antibiotics, into the aqueous $\mathrm{CuSO}_{4}$ solution in. the presence of phosphate buffer saline (PBS). Figure 1a and $\mathrm{S} 1$ reveals the morphology obtained and isolated after $\mathrm{CuSO}_{4}$ was present in $\mathrm{PBS}$ buffer following the procedure outlined in the experimental section, it is observed that no structures are formed without the addition of Kanamycin. When a certain amount of Kanamycin was introduced into the PBS-containing $\mathrm{CuSO}_{4}$ solution, green precipitates were observed after 1 day. These green precipitates had uniform flower structures with an average diameter of $4 \mu \mathrm{m}$ and a petal thickness of less than $10 \mathrm{~nm}$ (Figure b,c \& d). This flower-like morphology has high surface to volume ratio, and the structures observed showed good monodispersity. The effect of Kanamycin concentration on the morphology of the hybrid structures is shown in Fig. S2. At a low concentration of $20 \mu \mathrm{l}$ Kanamycin (120 mM), a uniform flower-like morphology is observed as illustrated in Fig. S2a. A further increase of Kanamycin concentration leads to the flower structures starting to aggregate at Kanamycin additions of 40 and $60 \mu \mathrm{l}$ (Figure S2b,c) and finally microsheet structures are observed with Kanamycin additions of 80 and $100 \mu \mathrm{l}$ (Fig. 1Sd\&e). 

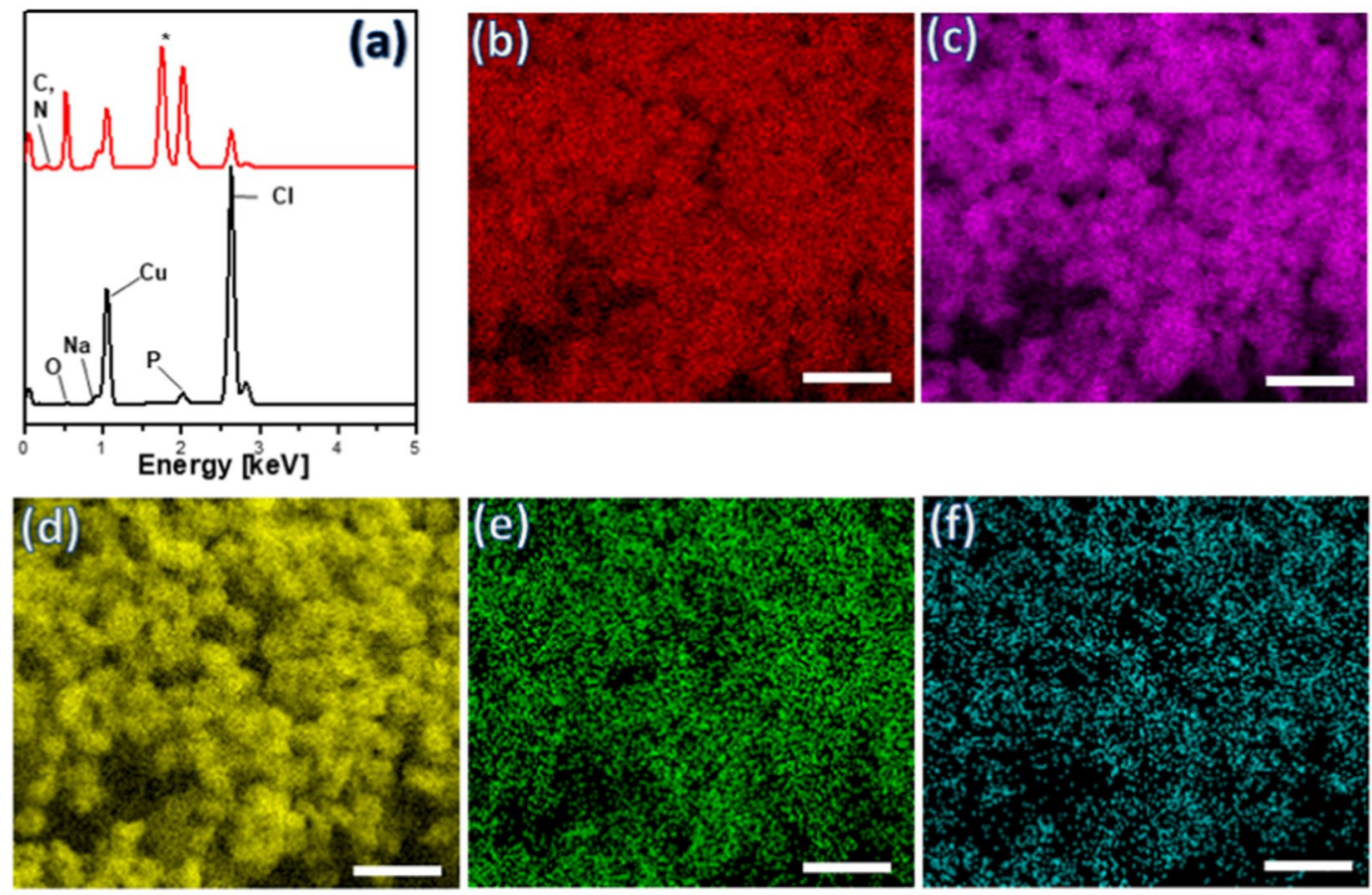

Figure 2. (a) EDS spectra of $\mathrm{Cu}_{3}\left(\mathrm{PO}_{4}\right)_{2}$ crystals (black line) and kanamyci- $\mathrm{Cu}_{3}\left(\mathrm{PO}_{4}\right)_{2}$ hybrid flowers (red line), with the EDS element mapping of (b) Cu, (c) P, (d) O, (e) C, (f) N with scale bar of $10 \mu \mathrm{m}$.

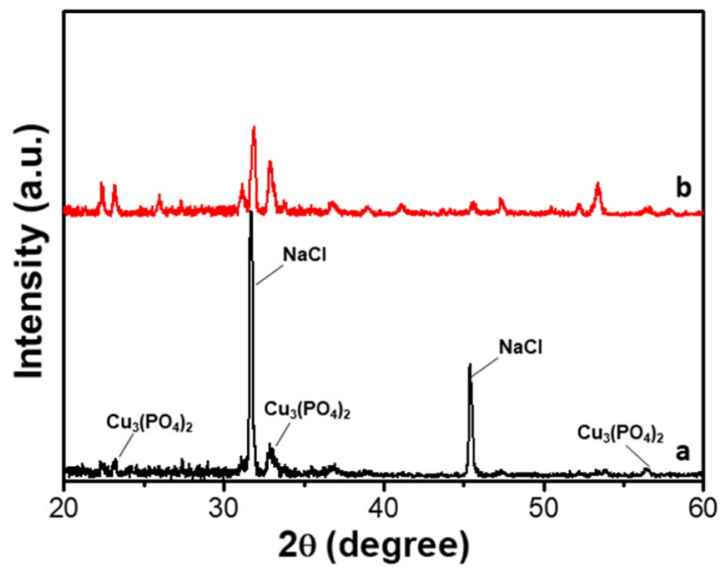

Figure 3. $\mathrm{XRD}$ patterns of $\mathrm{Cu}_{3}\left(\mathrm{PO}_{4}\right)_{2}$ crystals (black line) and kanamycin- $\mathrm{Cu}_{3}\left(\mathrm{PO}_{4}\right)_{2}$ hybrid flowers (red line).

Energy Dispersive Spectroscopy (EDS) was utilized to confirm the elemental composition of the isolated structures. Figure 2a shows the EDS patterns of the precipitates before and after addition of kanamycin, with the appearances of $\mathrm{C}$ and $\mathrm{N}$ peaks confirming the formation of kanamycin-inorganic hybrid structures in the final product. Furthermore, the elemental mapping (Fig. 2b-f) demonstrates that $\mathrm{C}, \mathrm{N}, \mathrm{Cu}, \mathrm{P}$ and $\mathrm{O}$ elements are homogeneously distributed throughout the hybrid flower. This may be attributed to complex formation between kanamycin and $\mathrm{Cu}_{3}\left(\mathrm{PO}_{4}\right)_{2} \cdot 3 \mathrm{H}_{2} \mathrm{O}^{30}$.

The crystallinity of the kanamycin-inorganic hybrid flowers was investigated by collection of XRD patterns (Fig. 3 \& S3). It is clear shown in Fig. S3 that the Kanamycin monomer is amorphous in nature. The peaks that appeared in the XRD pattern of the sample without kanamycin (black line in Fig. 3) confirms the presence of $\mathrm{Cu}_{3}\left(\mathrm{PO}_{4}\right)_{2}$ and $\mathrm{NaCl}$ crystals. In the XRD pattern of the hybrid flowers (red line), it can be seen that besides the existence of peaks for $\mathrm{Cu}_{3}\left(\mathrm{PO}_{4}\right)_{2}$ and $\mathrm{NaCl}$, extra diffraction peaks are observed, that confirms the existence of ordered structures in the kanamycin-inorganic hybrid flowers, indicating that directed growth through non-covalent interactions has led to crystallinity in the flowers.

The formation of the kanamycin-inorganic hybrid flowers was also studied by FTIR spectroscopy. Figure 4 shows the FTIR spectra of $\mathrm{Cu}_{3}\left(\mathrm{PO}_{4}\right)_{2}$ and kana-Cu $3\left(\mathrm{PO}_{4}\right)_{2}$ hybrid flowers. In the FTIR spectrum of $\mathrm{Cu}_{3}\left(\mathrm{PO}_{4}\right)_{2}$ (black line), the broad sketching at $1657 \mathrm{~cm}^{-1}$ is attributed to adsorbed water. The characteristic peaks at 1153 , 


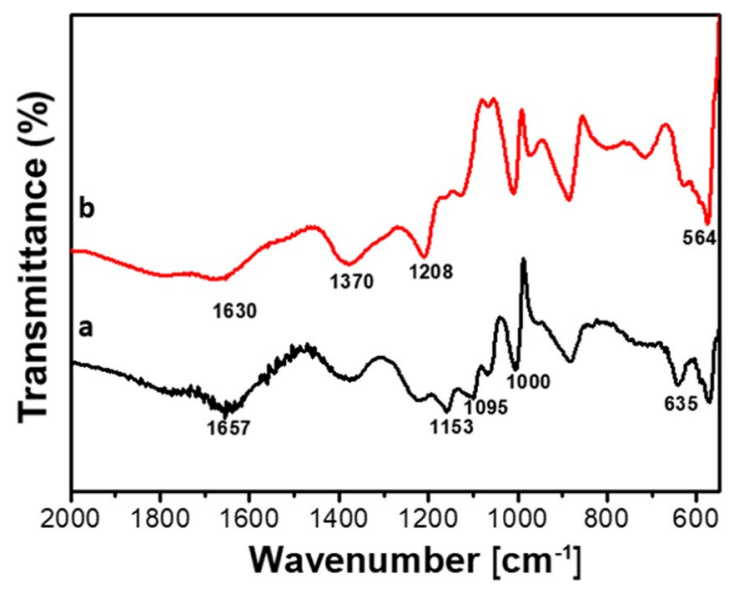

Figure 4. FTIR spectra of $\mathrm{Cu}_{3}\left(\mathrm{PO}_{4}\right)_{2}$ crystals (black line) and kanamycin- $\mathrm{Cu}_{3}\left(\mathrm{PO}_{4}\right)_{2}$ hybrid flowers (red line).

1095 and $1000 \mathrm{~cm}^{-1}$ are assigned to the bending vibrations of $\mathrm{Cu}-\mathrm{OH}$ (asymmetric), and symmetric $\mathrm{O}=\mathrm{P}$ and $\mathrm{P}-\mathrm{O}$ stretching vibrations, respectively ${ }^{27,31}$. The characteristic bands at 564 and $635 \mathrm{~cm}^{-1}$ are assigned to the $\mathrm{O}=\mathrm{P}-\mathrm{O}$ bridging phosphorous, and confirm the presence of phosphate groups ${ }^{32}$. In the FTIR spectrum of the kanamycin- $\mathrm{Cu}_{3}\left(\mathrm{PO}_{4}\right)_{2}$ hybrid flowers (red line), while the characteristic peaks at 1153, 1095, 1000, 635 and $564 \mathrm{~cm}^{-1}$ demonstrate the presence of the $\mathrm{Cu}_{3}\left(\mathrm{PO}_{4}\right)_{2}$, the bending vibration at $1208 \mathrm{~cm}^{-1} \mathrm{can}$ be assigned to phenyl ring-carbon sketching ${ }^{33}$, which further confirms the presence of kanamycin molecules within the hybrid flowers. Furthermore, no obvious new characteristic peaks are observed in the FTIR spectrum of kanamycin- $\mathrm{Cu}_{3}\left(\mathrm{PO}_{4}\right)_{2}$ hybrid flowers, confirming the self-assembly pathway to form the flower structures, instead of covalent bonding.

Figure 5 illustrates the step-wise growth of kanamycin- $\mathrm{Cu}_{3}\left(\mathrm{PO}_{4}\right)_{2}$ hybrid flowers upon addition of Kanamycin into the PBS-buffered $\mathrm{Cu}^{2+}$ solution at various stages of flower growth. It can be observed that the hybrid flowers initially nucleate on a small site, and then gradually grow into the full flower-like structures via directed growth of the petals. It is a reasonable assumption that the coordination between the antibiotic and $\mathrm{Cu}^{2+}$ is the main driving force for the formation of hybrid flowers. The amine groups in the kanamycin compounds can complex with $\mathrm{Cu}^{2+}$, leading to growth of the petals. At the beginning, the amine moieties are diluted in aqueous media to form separate sites on the surface of kanamycin backbone. Then these amine moieties coordinate with the $\mathrm{Cu}^{2+}$ binding sites of the copper phosphate to form the separate petals, which eventually shape into full hybrid flowers.

Copper phosphate-based materials have been previously shown to have good photocatalytic properties ${ }^{34,35}$, due to their broad visible light absorption range. In this work, the photocatalytic behavior of the kanamycin$\mathrm{Cu}_{3}\left(\mathrm{PO}_{4}\right)_{2}$ hybrid flowers for the degradation of methyl blue $(\mathrm{MB})$ was studied as a model reaction, and results are shown in Fig. 6 and Figure S5. The decrease in the absorption peak at $653 \mathrm{~nm}$ as a function of time due to MB degradation was employed to assess the photocatalytic activity. Illustrated in Figure $\mathrm{S} 5$ is the $\mathrm{C} / \mathrm{C}_{\mathrm{o}}$ versus time plot of $\mathrm{MB}$ under various photocatalytic conditions, where $\mathrm{C}_{\mathrm{o}}$ is the initial concentration of the dye and $\mathrm{C}$ is the concentration at time $t$. The absorption spectrum of $\mathrm{MB}$ solution and kanamycin- $\mathrm{Cu}_{3}(\mathrm{PO} 4)_{2}$ hybrid flowers in water are illustrated in Figure S4 indicating that the hybrid flowers show no dissolution in the water. Figure 6a is the absorption spectrum of the mixed solution of $\mathrm{MB}$ and kanamycin- $\mathrm{Cu}_{3}(\mathrm{PO} 4)_{2}$ hybrid flowers after exposed to the light source with different time. It is apparent from Fig. $6 \mathrm{a}$ and S5 that the hybrid flowers display excellent photocatalytic performance for the degradation of $\mathrm{MB}$, as after 240 minutes of irradiation time under visible light, virtually $100 \%$ of the MB has degraded. No degradation of the MB dye was observed without using the photocatalyst, which suggests that there is no self-sensitized degradation of MB occurring under these conditions. The kinetics of the photocatalytic reaction of kanamycin- $\mathrm{Cu}_{3}\left(\mathrm{PO}_{4}\right)_{2}$ hybrid flowers for the degradation of $\mathrm{MB}$ were investigated through the plot of $\ln \left(A_{t} / A_{0}\right)$ vs. time, where $A_{o}$ is the intensity at time zero, and $A_{t}$ is the peak intensity at time $\mathrm{t}$ (Fig. 6b). It can be calculated from the plot that the degradation rate constant of the $\mathrm{MB}$ by kanamycin- $\mathrm{Cu}_{3}\left(\mathrm{PO}_{4}\right)_{2}$ hybrid flowers is $15 \times 10^{-3} \mathrm{~min}^{-1}$, which is comparative with other reported photocatalysts $^{36-38}$.

It is well known that copper phosphate nanomaterials display good photocatalytic performance under visible light irradiation ${ }^{34,35}$. With incorporation of kanamycin with copper phosphate, flower-like materials with a higher surface area have been fabricated, which is responsible for enhanced photocatalytic performance. The complexation of the kanamycin molecule with copper phosphate may also broaden the light absorbing region, as well as increase the charge separation ability of the resultant photocatalyst to enhance the photocatalytic activity. Based on the literature and this concept, we propose a possible photocatalytic mechanism of the kanamycin-copper phosphate hybrid flowers for the degradation of organic dyes as shown in Fig. 7. Under visible light irradiation, the kanamycin-copper phosphate hybrid flowers generate electrons/holes pairs by the moving of electrons through bandgap energy from the valence band to the conduction band of the hybrid flowers ${ }^{39}$. The generated holes move to the surface of the petals to react with $\mathrm{H}_{2} \mathrm{O}$ or $\mathrm{OH}^{-}$to form active species such as. $\mathrm{OH}$, and these species will reduce the dye molecules to less harmful degraded products ${ }^{40}$. On the other side of the reaction, the generated electrons will oxidize oxygen in water to form $\mathrm{O}_{3}{ }^{-}$radicals ${ }^{37,41}$. 

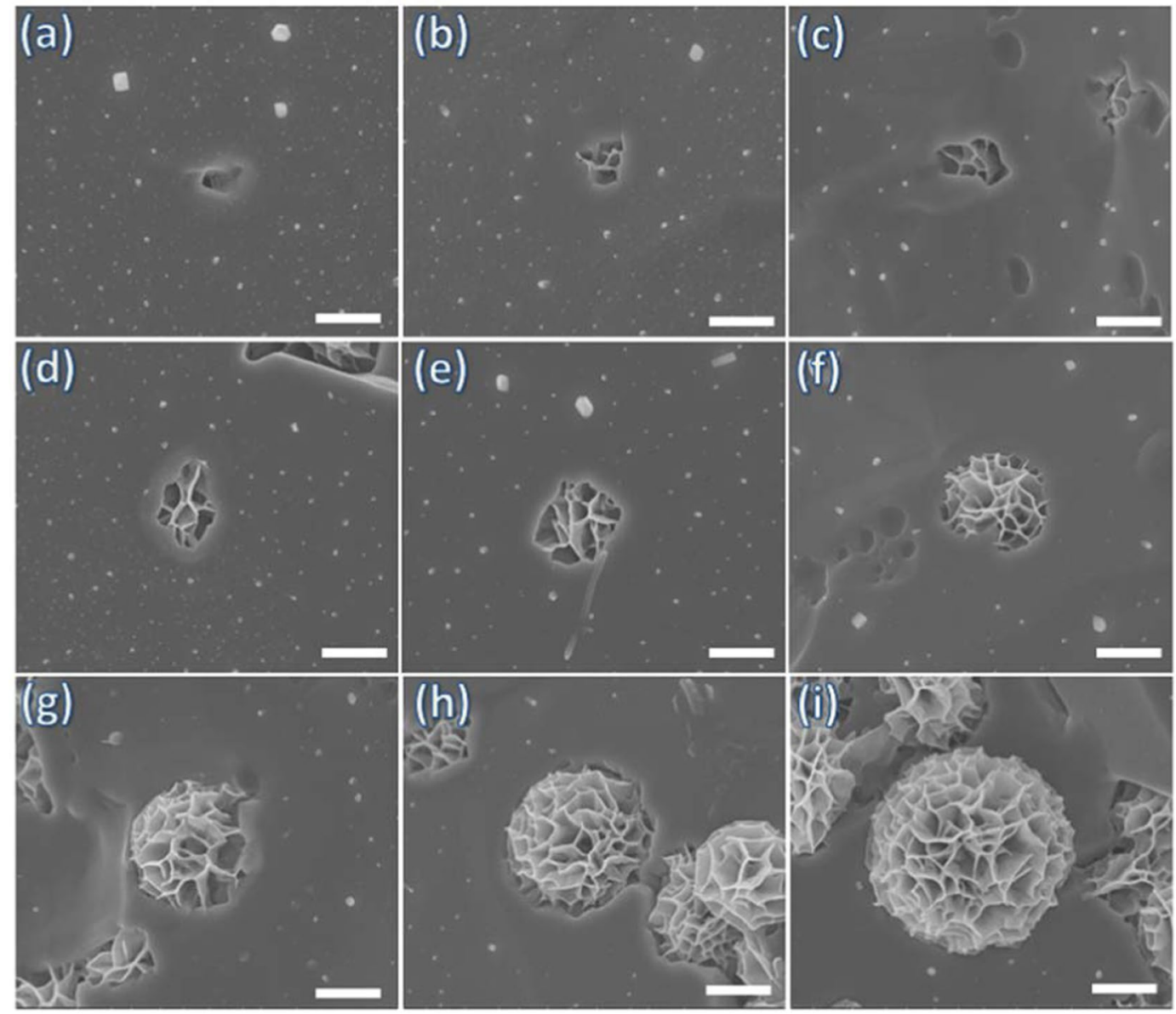

Figure 5. Step-wise nucleation and growth mechanism of the Kanamycin- $\mathrm{Cu}_{3}\left(\mathrm{PO}_{4}\right)_{2}$ hybrid flowers with time interval of 1 hour for each step-wise growth. Scale bar is $1 \mu \mathrm{m}$.
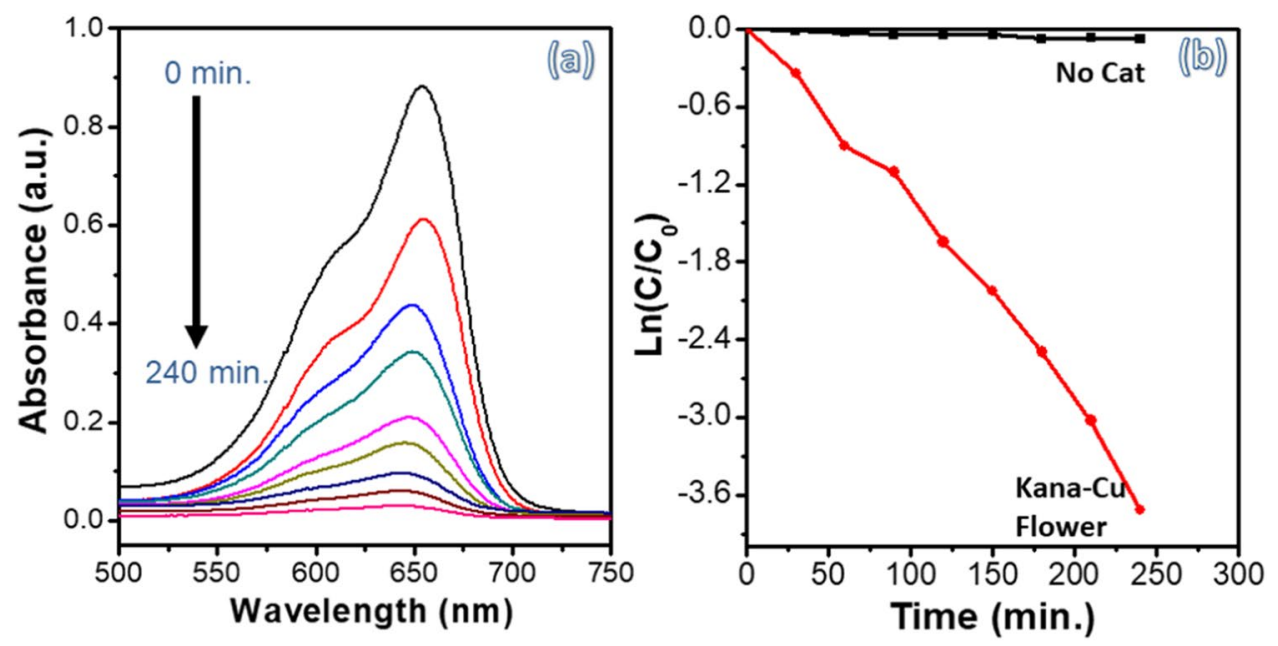

Figure 6. (a) Photocatalytic performance and (b) kinetic simulation curve for methyl blue by Kanamycin$\mathrm{Cu}_{3}\left(\mathrm{PO}_{4}\right)_{2}$ hybrid flowers for $\mathrm{MB}$ degradation.

In summary, the growth mechanism from nucleation to a full flower structure was studied by SEM studies, indicating that the coordination between amine moieties in kanamycin and $\mathrm{Cu}^{2+}$ was responsible for the nucleation and growth of flower petals, eventually leading to a full flower structure. We have successfully fabricated an organic-inorganic hybrid flower-like structure by complexation between a common antibiotic (kanamycin) and 


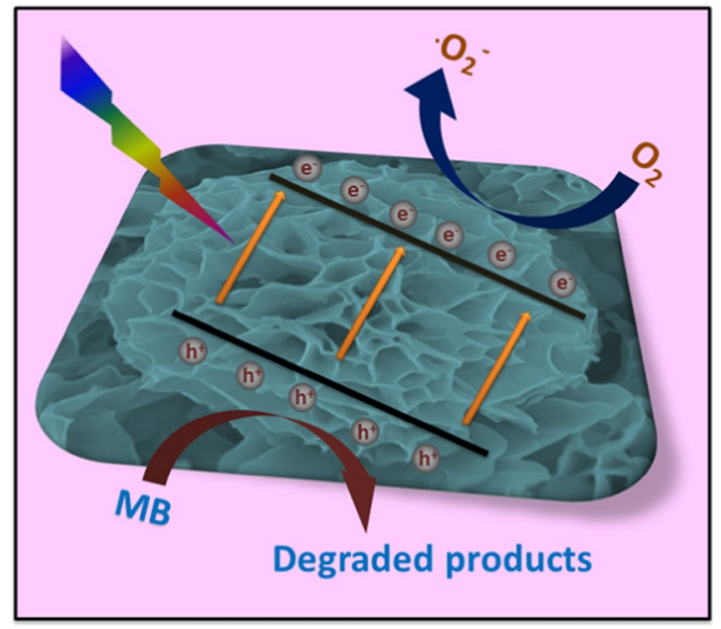

Figure 7. Possible photocatalytic mechanism of Kanamycin- $\mathrm{Cu}_{3}\left(\mathrm{PO}_{4}\right)_{2}$ hybrid flowers as photocatalyst toward methyl blue dye.

$\mathrm{Cu}^{2+}$ in PBS solution. The resultant kanamycin- $\mathrm{Cu}_{3}\left(\mathrm{PO}_{4}\right)_{2}$ complex has a uniform flower-like structure with an average diameter of $4 \mu \mathrm{m}$ and a petal thickness of less than $10 \mathrm{~nm}$. The coordination between $\mathrm{Cu}^{2+}$ ions and amine groups in the kanamycin is the main driving force for formation of the flower-like morphology. The kanamycin$\mathrm{Cu}_{3}\left(\mathrm{PO}_{4}\right)_{2}$ hybrid flower revealed remarkable photocatalytic activity for the removal of methylene blue under simulated sunlight irradiation, with the degradation rate constant of $15 \times 10^{-3} \mathrm{~min}^{-1}$, which is comparative with reported photocatalysts. The kanamycin- $\mathrm{Cu}_{3}\left(\mathrm{PO}_{4}\right)_{2}$ hybrid flower can be considered as a modified semiconductor material, which can absorb the light energy in visible region to generate e/h pairs for the degradation of methyl blue dye. With such a high photocatalytic performance, the organic-inorganic supramolecular flowers are promising photocatalyst for environmental treatment of contaminated wastewaters, as well as a contribution that provides insight into the construction of three-dimensional (3D) hierarchical nanostructures. We are currently working on self-assembly of kanamycin and other antibiotics with various metals, which may lead to a deeper understanding of the underlying mechanism that leads to the excellent photocatalytic performance of this antibiotic-inorganic hybrid flower.

\section{Experimental Section}

Materials and methods. Kanamycin was obtained from TCI, Chennai, India. Copper sulfate $\left(\mathrm{Cu}_{2} \mathrm{SO}_{4}\right)$, phosphoric acid $\left(\mathrm{H}_{3} \mathrm{PO}_{4}\right.$, sodium chloride $(\mathrm{NaCl})$, potassium chloride $(\mathrm{KCl})$, methyl blue $(\mathrm{MB})$ and ethanol were obtained from Ajax Finechem (Australia). All chemicals were utilized without any further purification. The nanostructured morphology, composition, as well as elemental distribution in kana- $\mathrm{Cu}_{3}\left(\mathrm{PO}_{4}\right)_{2}$ hybrid flowers were studied by scanning electron microscopy (SEM), Energy Dispersive spectroscopy (EDS) and EDS mapping using an EDS-integrated FEI Nova NanoSEM (Hillsboro, USA, operating under HV and Stage bias condition of $15 \mathrm{KeV}$, samples were coated with Pt) and an Everhart Thornley Detector (ETD). Ultraviolet-visible (UV-Vis) absorption measurements of samples in solution were collected using a Cary 50 Bio spectrophotometer with a cell of $1 \mathrm{~cm}$ path length. A BrukerAXS D8 Discover instrument with a general area detector diffraction system (GADDS) using a $\mathrm{Cu} \mathrm{K} \alpha$ source was utilized to obtain XRD patterns of the hybrid flowers. Fourier transform infrared (FTIR) measurements were performed on a PerkinElmer D100 spectrometer in attenuated total reflectance mode.

Synthesis of kanymicin- $\mathrm{Cu}_{3}\left(\mathrm{PO}_{4}\right)_{2}$ hybrid flowers. In the typical procedure for the synthesis of the hybrid flower-like structures, various concentrations of kanamycin were prepared by diluting kanamycin in $3 \mathrm{ml}$ of phosphate buffer saline (PBS, pH 7.4). Then, $20 \mathrm{ml}$ of aqueous $\mathrm{Cu}^{2+}$ solution $(120 \mathrm{mM})$ was gradually introduced into the kanamycin solution. The mixed solution was incubated for 1 day under ambient conditions. The precipitate was filtered, rinsed and dried thoroughly, and kept in the dark for further characterization.

Photocatalytic investigation. The photocatalytic performance of the kana- $\mathrm{Cu}_{3}\left(\mathrm{PO}_{4}\right)_{2}$ hybrid flowers was investigated for the methyl blue degradation in aqueous solution. In a typical photocatalytic measurement, $0.1 \mathrm{mg}$ of c kana- $\mathrm{Cu}_{3}\left(\mathrm{PO}_{4}\right)_{2}$ hybrid flowers was added into a $20 \mathrm{~mL}$ aqueous solution of the $5 \mathrm{mg} \mathrm{L}^{-1}$ methyl blue. The mixed solution was magnetically stirred for 30 minutes and left overnight in the dark to reach an equilibrium state before carrying out the photocatalytic reaction. The visible light source for the photocatalytic experiment is a $300 \mathrm{~W}$ air cooled Xenon lamp. At certain time points, $1.5 \mathrm{~mL}$ of mixed solution were taken out and centrifuged to remove the kana- $\mathrm{Cu}_{3}\left(\mathrm{PO}_{4}\right)_{2}$ hybrid flowers. The photocatalytic performance for the $\mathrm{MB}$ removal was assessed by determine the absorbance at a wavelength of $653 \mathrm{~nm}$. For the practical application, the kana- $\mathrm{Cu}_{3}\left(\mathrm{PO}_{4}\right)_{2}$ hybrid flowers can be separated by centrifugation and use for the next cycle application.

Received: 26 July 2019; Accepted: 10 December 2019;

Published online: 13 January 2020 


\section{References}

1. Leung, K. C.-F. et al. Gold and iron oxide hybrid nanocomposite materials. Chem. Soc. Rev. 41, 1911-1928 (2012).

2. Goskulwad, S. P. et al. Supramolecular Chiral Helical Ribbons of Tetraphenylethylene-Appended Naphthalenediimide Controlled by Solvent and Induced by l-and d-Alanine Spacers. Chem. Asian J. 13, 3947-3953 (2018).

3. Bai, Z. et al. 3D-Branched ZnO/CdS Nanowire Arrays for Solar Water Splitting and the Service Safety Research. Adv. Energy Mater. 6, 1501459 (2016).

4. La, D. D., Bhosale, S. V., Jones, L. A. \& Bhosale, S. V. Tetraphenylethylene-based AIE-active probes for sensing applications. ACS Appl. Mater. Interfaces 10, 12189-12216 (2017).

5. Ma, C.-B. et al. MoS 2 nanoflower-decorated reduced graphene oxide paper for high-performance hydrogen evolution reaction. Nanoscale 6, 5624-5629 (2014).

6. King'ondu, C. K. et al. Light-assisted synthesis of metal oxide heirarchical structures and their catalytic applications. J. Am. Chem. Soc. 133, 4186-4189 (2011).

7. Salimimarand, M., La, D. D., Al Kobaisi, M. \& Bhosale, S. V. Flower-like superstructures of AIE-active tetraphenylethylene through solvophobic controlled self-assembly. Sci. Rep. 7, 42898 (2017).

8. Kim, S.-I., Lee, J.-S., Ahn, H.-J., Song, H.-K. \& Jang, J.-H. Facile route to an efficient NiO supercapacitor with a three-dimensional nanonetwork morphology. ACS Appl. Mater. Interfaces 5, 1596-1603 (2013).

9. Thongtem, S., Singjai, P., Thongtem, T. \& Preyachoti, S. Growth of carbon nanoflowers on glass slides using sparked iron as a catalyst. Mater. Sci. Eng. A 423, 209-213 (2006).

10. Du, J. et al. Carbon nanoflowers synthesized by a reduction-pyrolysis-catalysis route. Mater. Lett. 59, 456-458 (2005).

11. Cha, S. I., Mo, C. B., Kim, K. T. \& Hong, S. H. Ferromagnetic cobalt nanodots, nanorices, nanowires and nanoflowers by polyol process. J. Mater. Res. 20, 2148-2153 (2005).

12. Wang, Z., Zhang, J., Ekman, J. M., Kenis, P. J. \& Lu, Y. DNA-mediated control of metal nanoparticle shape: one-pot synthesis and cellular uptake of highly stable and functional gold nanoflowers. Nano Lett. 10, 1886-1891 (2010).

13. Bian, J. et al. Reproducible and recyclable SERS substrates: Flower-like Ag structures with concave surfaces formed by electrodeposition. Appl. Surf. Sci. 333, 126-133 (2015).

14. Zeng, M. et al. Cu doped OL-1 nanoflower: a UV-vis-infrared light-driven catalyst for gas-phase environmental purification with very high efficiency. Appl. Catal. B 200, 521-529 (2017).

15. Huang, K.-J., Liu, Y.-J., Liu, Y.-M. \& Wang, L.-L. Molybdenum disulfide nanoflower-chitosan-Au nanoparticles composites based electrochemical sensing platform for bisphenol A determination. J. Hazard. Mater. 276, 207-215 (2014).

16. He, S., Hu, C., Hou, H. \& Chen, W. Ultrathin MnO2 nanosheets supported on cellulose based carbon papers for high-power supercapacitors. J. Power Sources 246, 754-761 (2014).

17. Liu, Y. et al. Hierarchical $\mathrm{SnO} 2$ nanostructures made of intermingled ultrathin nanosheets for environmental remediation, smart gas sensor, and supercapacitor applications. ACS Appl. Mater. Interfaces 6, 2174-2184 (2014).

18. Whitesides, G. M. et al. Noncovalent Synthesis: Using Physical-Organic Chemistry To Make Aggregates. Acc. Chem. Res. 28, 37-44, https://doi.org/10.1021/ar00049a006 (1995).

19. Hoeben, F. J. M., Jonkheijm, P., Meijer, E. W. \& Schenning, A. P. H. J. About Supramolecular Assemblies of $\pi$-Conjugated Systems. Chem. Rev. 105, 1491-1546, https://doi.org/10.1021/cr030070z (2005).

20. Ulijn, R. V. \& Smith, A. M. Designing peptide based nanomaterials. Chem. Soc. Rev. 37, 664-675, https://doi.org/10.1039/B609047H (2008).

21. Vriezema, D. M. et al. Self-Assembled Nanoreactors. Chem. Rev. 105, 1445-1490, https://doi.org/10.1021/cr0300688 (2005).

22. Barron, L. D. Symmetry and molecular chirality. Chem. Soc. Rev. 15, 189-223, https://doi.org/10.1039/CS9861500189 (1986).

23. Huang, X. et al. Interfacial assembly of protein-polymer nano-conjugates into stimulus-responsive biomimetic protocells. Nat. Commun. 4, 2239 (2013).

24. Sun, J. et al. Multi-enzyme co-embedded organic-inorganic hybrid nanoflowers: synthesis and application as a colorimetric sensor. Nanoscale 6, 255-262 (2014).

25. Wang, L.-B. et al. A new nanobiocatalytic system based on allosteric effect with dramatically enhanced enzymatic performance. J. Am. Chem. Soc. 135, 1272-1275 (2013).

26. Zhu, X. et al. A dual enzyme-inorganic hybrid nanoflower incorporated microfluidic paper-based analytic device ( $\mu$ PAD) biosensor for sensitive visualized detection of glucose. Nanoscale 9, 5658-5663 (2017).

27. Yin, Y. et al. An enzyme-inorganic hybrid nanoflower based immobilized enzyme reactor with enhanced enzymatic activity. J. Mater. Chem. B 3, 2295-2300 (2015).

28. Rong, J., Zhang, T., Qiu, F. \& Zhu, Y. Preparation of efficient, stable, and reusable laccase-Cu3 (PO4) 2 hybrid microspheres based on copper foil for decoloration of congo red. ACS Sustain. Chem. Eng. 5, 4468-4477 (2017).

29. Ge, J., Lei, J. \& Zare, R. N. Protein-inorganic hybrid nanoflowers. Nat. Nanotechnol. 7, 428 (2012).

30. Jiao, J. et al. Self-assembly of biosurfactant-inorganic hybrid nanoflowers as efficient catalysts for degradation of cationic dyes. RSC Adv. 7, 43474-43482 (2017).

31. He, G., Hu, W. \& Li, C. M. Spontaneous interfacial reaction between metallic copper and PBS to form cupric phosphate nanoflower and its enzyme hybrid with enhanced activity. Coll. Surf. B Biointerf. 135, 613-618 (2015).

32. Lin, Z. et al. Facile synthesis of enzyme-inorganic hybrid nanoflowers and their application as an immobilized trypsin reactor for highly efficient protein digestion. RSC Adv. 4, 13888-13891 (2014).

33. Surekha, R., Gunaseelan, R., Sagayaraj, P. \& Ambujam, K. L-phenylalanine L-phenylalaninium bromide-a new nonlinear optical material. Cryst. Eng. Comm. 16, 7979-7989 (2014).

34. Yang, S. et al. Solution growth of peony-like copper hydroxyl-phosphate (Cu2 (OH) PO4) flowers on Cu foil and their photocatalytic activity under visible light. Mater. Des. 100, 30-36 (2016).

35. Zhao, D. et al. Surface modification of TiO2 by phosphate: effect on photocatalytic activity and mechanism implication. J. Phys. Chem. C 112, 5993-6001 (2008).

36. La, D. et al. Arginine-Mediated Self-Assembly of Porphyrin on Graphene: A Photocatalyst for Degradation of Dyes. Appl. Sci. 7, 643 (2017).

37. La, D. D., Bhosale, S. V., Jones, L. A. \& Bhosale, S. V. Arginine-induced porphyrin-based self-assembled nanostructures for photocatalytic applications under simulated sunlight irradiation. Photochem. Photobiol. Sci. 16, 151-154 (2017).

38. La, D. D., Rananaware, A., Salimimarand, M. \& Bhosale, S. V. Well-dispersed assembled porphyrin nanorods on graphene for the enhanced photocatalytic performance. ChemistrySelect 1, 4430-4434 (2016).

39. La, D. D., Ramanathan, R., Rananaware, A., Bansal, V. \& Bhosale, S. V. Nanostructured charge transfer complex of CuTCNQF 4 for efficient photo-removal of hexavalent chromium. RSC Advances 6, 33931-33936 (2016).

40. Chen, Y., Huang, Z.-H., Yue, M. \& Kang, F. Integrating porphyrin nanoparticles into a 2D graphene matrix for free-standing nanohybrid films with enhanced visible-light photocatalytic activity. Nanoscale 6, 978-985 (2014).

41. Li, D., Dong, W., Sun, S., Shi, Z. \& Feng, S. Photocatalytic degradation of acid chrome blue K with porphyrin-sensitized TiO2 under visible light. J. Phys. Chem. C 112, 14878-14882 (2008). 


\section{Acknowledgements}

R.W.J. acknowledges UGC for NET-Junior Research Fellowship. D.D.L thanks to NAFOSTED, coded: 104.052019.01. S.V.B. (GU) University Grant Commission (UGC) Faculty Research Program, New Delhi, India for an award of Professorship and also acknowledges Council of Scientific \& Industrial Research (CSIR), India for providing support, code No. 02(0357)/19/EMR-II. We acknowledge Dr. Lathe A. Jones (RMIT) for proof reading.

\section{Author contributions}

R.W.J. performed synthesis of hybrid material, establish self-assembly process and also done IR, UV-vis study along with experimental write-up. D.D.L. performed SEM imaging and photocatalysis activity. D.A.N., H.T.V. and V.G.M. performed X.R.D. and E.D.S. mapping, D.L.T. supervise D.D.L. and D.A.N., S.V.B. designed the experiments, directed, interpreted and analyses the data and drafted the manuscript. All co-authors reviewed the manuscript.

\section{Competing interests}

The authors declare no competing interests.

\section{Additional information}

Supplementary information is available for this paper at https://doi.org/10.1038/s41598-019-57044-Z.

Correspondence and requests for materials should be addressed to S.V.B.

Reprints and permissions information is available at www.nature.com/reprints.

Publisher's note Springer Nature remains neutral with regard to jurisdictional claims in published maps and institutional affiliations.

Open Access This article is licensed under a Creative Commons Attribution 4.0 International License, which permits use, sharing, adaptation, distribution and reproduction in any medium or format, as long as you give appropriate credit to the original author(s) and the source, provide a link to the Creative Commons license, and indicate if changes were made. The images or other third party material in this article are included in the article's Creative Commons license, unless indicated otherwise in a credit line to the material. If material is not included in the article's Creative Commons license and your intended use is not permitted by statutory regulation or exceeds the permitted use, you will need to obtain permission directly from the copyright holder. To view a copy of this license, visit http://creativecommons.org/licenses/by/4.0/.

(C) The Author(s) 2020 